\title{
A case report on club foot (Congenital Talipes Equino Varus (CTEV))
}

\begin{abstract}
Under the Rastriya Bal Swastya Karyakram (RBSK) programme in Anganwadi School, a school health check up was conducted in Lekmashi Mandal, Hindupur by the AYUSH team (ID PEN-A2) on January 2019. During this programme a 2 months male baby was diagnosed as of club foot. Clubfoot is one of the most common congenital abnormity affecting the lower limb with an incidence of one to two per 1000 live births. It remains a challenge not only to understand its genetic origin, but also to provide effective long term treatment. Its etiology remains unclear. According to the parents history the baby was born with club foot and treated in corporate hospitals. But there was no response. The team thoroughly examined, diagnosed and referred the baby to District Early Intervention Centre (DEIC), Anantapur for the management. Conservative treatment was given with weekly follow up. Now the baby can bear his weight on his heel with support.
\end{abstract}

Keywords: RBSK school health programme, clubfoot, antenatal care, dietary deficiency, prevention and management
Volume 9 Issue 4 - 2019

\author{
Yasmin K, Tabassum K, Mahalakshmi, Arpita \\ RBSK Team, Lepakshi Mandal, India
}

Correspondence: Tabassum K, RBSK Team, Lepakshi Mandal, India, Email drtabassum.nium@gmail.com

Received: June 20, 2019 | Published: July 29, 2019
Abbreviations: CTEV, Congenital Talipes Equino Varus; RBSK, rastriya bal swastya karyakram; DEIC, district early intervention centre

\section{Introduction}

Club foot also known as Congenital Talipes Equino Varus (CTEV) was introduced in the medical literature by Hippocrates around 300 B.C. The incidence of CTEV is 1-2/1000 live births. The involvement is bilateral in about $50 \%$ of cases and in unilateral cases the right side is affected slightly more than left. ${ }^{1}$ A normal developing foot turns into a clubfoot during the second trimester of pregnancy. Clubfoot is not an embryonic abnormality. According to theory of Hippocrates, due to the compression of uterus, foot got the position of equinovarus. However, Parker and Browne believed that oligohydramnios restrict the movement of foetus. Club foot may be due to arrest of intra uterine fetal development because of dietary deficiency or certain obstetric conditions or environmental harmful teratogenic agents. Exposure to cigarette smoke and family history of smoking is also considered as the causative factor for the club foot especially in antenatal period. Idiopathic clubfoot is approximately twice as common in males as in females. Clubfoot is an obvious deformity easily recognized. It has four components i.e talipes equius, mid foot cavus, forefoot adduction and hind foot varus. The deformity in idiopathic club foot is both cosmetic and functional with associated hypoplasia of skin, muscles, tendons, bones, ligaments and neurovascular bundle on the medial side and the affected foot is smaller than the normal foot. Clubfoot is usually diagnosed immediately after birth simply by inspection and examination of the foot. The initial treatment of a clubfoot should be nonsurgical and should be started as soon as possible after birth. Ponseti method is a specific method of casting, serial manipulation and surgery. Treatment is provided instantly after birth. The foot's ligament and tendon are stretched and manipulated on the weekly basis followed by implementation of the cast of soft fiber glass that helps to bring the ligament in its original position. If the manipulation or serial casting treatment fails, surgery is required. Surgical correction is usually not done until the child is between 6-9 months of age. Surgical treatment is performed to correct clubfoot and align the foot in original position. Here a case with club foot is discussed along with its prevention and management. ${ }^{2,3}$

Objective: The aim of the case report is

- To council and encourage the pregnant woman for regular antenatal check

- To encourage good dietary intake during pregnancy.

- To prevent congenital deformities of the baby

\section{Case report}

A 2 months male baby was diagnosed with club foot in school health check up, which was conducted under Rastriya Bal Swastya Karyakram (RBSK) programme on January 2019. According to the parent's history the baby was born with club foot and was managed in several hospitals. A detailed history regarding the antenatal check up, socio economic status, dietary intake and supplemental iron calcium, history of medical illness of the mother was taken. In family history smoking history of the father was found. The similar problem was found in other family members also. Through general and physical examination of the baby was done in different position to evaluate the extent of different abnormalities of CTEV. By standing whether the foot is plant grade, whether the heel is bearing weight and whether it is in varus or valgus. After examination the baby was diagnosed as Idiopathic clubfoot and referred to District Early Intervention Centre (DEIC) for the management. The foot's ligament and tendon were stretched and manipulated on the weekly basis followed by implementation of the cast of soft fiber glass that helps to bring the ligaments in their original position. Now the baby is bearing his weight on heel with support. (Figure 1) 

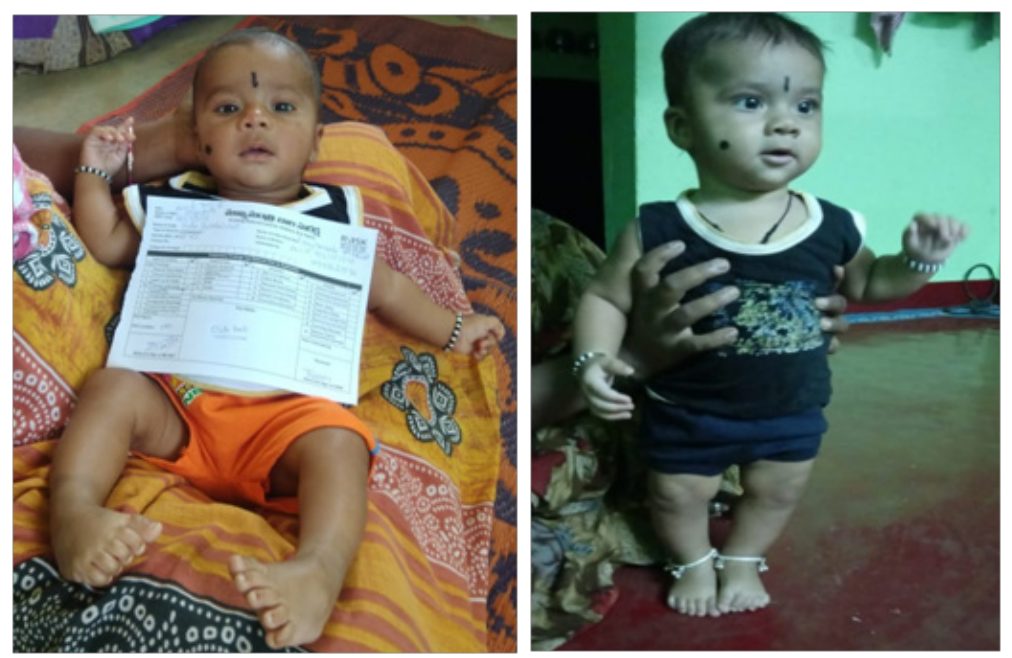

Figure I Before treatment and after treatment.

\section{Discussion}

Clubfoot may be associated with other congenital abnormalities but is usually an isolated finding which is idiopathic in nature. Multiple theories have been proposed to explain its etiology. One is that any arrest of the development of the foot during intrauterine life results in clubfoot. ${ }^{4,5}$ Ignacio V. Ponseti supported the "arrest of development" theory. This theory explains the harmful influence of teratogenic agents on fetal environment and development are well illustrated by the effect of rubella and thalidomide. Many authors believe that club foot and temporary growth arrest happens due to various environmental factors. ${ }^{6}$ Palmer supported multifactorial system of inheritance, possible with intrauterine factors having some effect. ${ }^{7}$ Wynne Davis supported the polygenic theory and showed a rapid decrease in incidence of clubfoot from first to third degree relatives. About $2.9 \%$ of siblings in the first degree relatives had this deformity as compared to $1-2 / 1000$ in general population that is, 25 times more chances in siblings of an affected child. ${ }^{8}$ Insley reported the association of clubfoot with a deficiency of a part of the long arm of chromosome eighteen. ${ }^{9}$ Environmental factors have also been implicated like hydroamnios or oligohydramnios, Infectious disease during pregnancy and maternal nutrition defects, vitamin deficiency, toxic agents like azaserine and maternal metabolic disorders which cause arrested intrauterine foetal development. ${ }^{1}$ Vitamin B12 is essential for the functioning of the nervous system. Women with low levels of B12 not only may risk health problems of their own, but also may increase the chance that their children may be born with a serious birth defect." Women of childbearing age, women in early pregnancy, and women who hope to become pregnant should take balanced diet includes foods rich in vitamin B12 or take supplements to reduce their risk of vitamin B12 deficiency and birth defects. ${ }^{9}$ In this case the patient belongs to lower middle class and had irregular antenatal check up. This may cause dietary deficient and poor health. This is the reason why the baby was developed club foot. Honein et al. reported the exposure of cigarette smoke and family history of smoking is as the causative factors for the club feet especially in Antenatal period. ${ }^{10}$ The conservative treatment with Ponseti method of clubfoot is well accepted and has been reported to result in good correction ranging from as low as $50 \%$ to as high as $90 \%{ }^{10}$

\section{Conclusion}

Clubfoot is one of the frequent conditions encountered in clinical practice. It is mainly due to dietary deficiency during antenatal period. Conservative management with ponseti technique has shown excellent result and decreased the requirement of surgery drastically. Current treatment of clubfoot deformity consists of initial trials of manipulation and serial casting. $30-50 \%$ feet treated in this way eventually needs surgical correction. On average of $25 \%$ of the operated feet will have poor results and will need secondary surgical intervention.

\section{Acknowledgment}

The AYUSH team was appreciated by Deputy DM\&HO Dr. Divakar, DM\&HO Dr. Aneel Kumar for early diagnosis and referral. The team acknowledge the Deputy DM\&HO and DM\&HO officers for their support. The team also acknowledge the Executive DEIC manager Dr. Rajeeta, Dr. Sujata, Dr. Naresh for their early intervention. The authors also would like to thank to the parents of the baby for their cooperation.

\section{Funding}

None.

\section{Conflict of interest}

There is no conflict of interest.

\section{References}

1. Wynne-Davis R. Family studies and the causes of congenital clubfoot: Talipes equinovarus, talipes calcaneal valgus, and metatarsus varus. $J$ Bone Joint Surg Br. 1964;46:445-463.

2. Ponseti IV, Smoley EN. Congenital club foot: The results of treatment. $J$ Bone Joint Surg Am. 1963;45(2):261-234.

3. Brockman E. Relapsed clubfoot by Dilwyn Evan's. J Bone Joint Surg. 1963;143:538-542.

4. Bohm M. Pathological anatomy of Clubfoot. J Bone Joint Surg. $1963 ; 45(1): 45-52$. 
5. Grant AD, Atar AD, Lehman WB. The Ilizarov technique in correction of complex foot deformities. Clin Orthop Relat Res. 1992;280:94-103.

6. Ippolito E, Ponseti IV. Congenital club foot in the human fetus. A histological study. J Bone Joint Surg. 1980;62(1):8-22.

7. Palmer RM. The genetics of talipes equinovarus. J Bone Joint Surg Am. 1964;46(3):542-556.
8. Wynne-Davies R. Family studies and aetiology of clubfoot. $J$ Med Genet. 1965;2(4):227-232.

9. Jenjifer W. Birth Defects Linked to Low Vitamin B12. Web Med cancer news letter, 2018.

10. Insley J. Syndrome associated with a deficiency of part of the long arm of chromosome. Arch Dis Child. 1967;42(222):140-146. 